\title{
PREPARATION AND CHARACTERIZATION OF $\beta$-CYCLODEXTRIN INCLUSION COMPLEXES ORAL TABLETS CONTAINING POORLY WATER SOLUBLE GLIMIPIRIDE USING FREEZE DRYING METHOD
}

\author{
Yandi Syukri*, Laryssa Fernenda, Fissy Rizki Utami, Isna Qiftayati, Aris Perdana \\ Kusuma, Rochmy Istikaharah
}

\begin{abstract}
Department of Pharmacy, Universitas Islam Indonesia, Jalan Kaliurang KM 14,5 Sleman Yogyakarta, 55584, Indonesia
\end{abstract}

Submitted: $25-12-2014$

Revised: $15-01-2015$

Accepted: 25-02-2015

*Corresponding author Yandi Syukri

Email:

yandi.sy@gmail.com

\begin{abstract}
Glimepiride is an oral antidiabetic drugs which is practically insoluble in water. The formation of $\beta$-cyclodextrin inclusion complex was able to increase the solubility of glimepiride. This study aim to prepare, characterize and formulation of inclusion complex tablets in order to meet the requirement in Pharmacopeia. The inclusion complex were prepared in a molar ratio of $1: 1$ and $1: 2$ by freeze drying method, after that characterized include FTIR spectroscopy and scanning electro microscope (SEM). Further, it was formulated into tablets by direct compression technique using primogel and crospovidone as super disintegrants. The tablets were evaluated include weight uniformity, hardness, friability, disintegration, and dissolution. The dissolution studies of inclusion complex were performed by using USP II apparatus. The result of FTIR and SEM provided evidence of the formation of complexes after utilizing freeze-drying methods. The tablet evaluation containing inclusion complex glimepiride- $\beta$ cyclodextrin with primogel and cropovidone as disintegrant showed that increased concentration of disintegrant will increase disintegration time of the tablets. All of formulas meet the requirements in the Pharmacopoeia. The inclusion complex of glimepiride- $\beta$ cyclodextrin successfully used for enhancing the solubility of glimepiride and the tablets meet the requirement in Pharmacopeia.
\end{abstract}

Keywords: Glimepirid, $\beta$-cyclodextrin, primogel, crospovidone

\section{INTRODUCTION}

The oral administration of drug is the most used to drug delivery in pharmacy due to its ease of administration, convenient, costeffectiveness and flexibility in design (Krishnaiah, 2010). Poor bioavailability of the drug is a major disadvantage of oral drug delivery due to low aqueous solubility and low drug permeability (Savjani et al., 2012). The poorly water soluble drug indicate low absorption and bioavailability is often controlled by the rate of dissolution of the drug in the gastrointestinal tract. Many approach has been done for enhancing the dissolution characteristics of slightly water-soluble drugs included reduce particle size, crystal modification, cyclodextrin complexation and self-emulsification (Kawabata et al., 2011). Solid dispersion also has been reported to increase dissolution of disulfiram and indomethacin (Ramadhani et al., 2014; Sunil et al., 2012).

Based on the various methods, cyclodextrin complexation has gained good acceptance in recent years in industry for enhancing the solubility and dissolution rate of poorly soluble drugs (Saravana Kumar et al., 2013). Cyclodextrin complexation has shown promising results in improving solubility, wettability, dissolution rate of drug and subsequently its bioavailability of products that are orally administered (Shanmuga Priya et al., 2013). Cyclodextrin have been developed to oral drug delivery for different objectives including reduction of gastrointestinal tract (GIT) irritation, unpleasant taste masking, and improvement of drug bioavailability through enhancement of the solubility and dissolution rate, and/or increased stability of the drug at the absorption site in the GIT (Challa et al., 
2005). Recently, complexation with cyclodextrins has been reported to enhance the solubility and dissolution rate of itraconazoe (Taupitz et al., 2013), curcumin (Michel et al., 2012), repaglanide (Liu et al., 2014), and myricetin (Yao et al., 2014).

The preparation methods of cyclodextrin inclusion compound commonly used are coprecipitation method, ultrasonic method, grinding method, spray-drying method, and freeze-drying method (Lee et al., 2010). The inclusion complexes omeprazole prepared with freeze-drying method produces true inclusion complexes better than kneading and spray drying method (Figueiras et al., 2007).

Glimepiride is one of the third generation sulfonylurea drugs useful to control of diabetes mellitus type 2 (Ammar et al., 2006). It has poor solubility and slow dissolution rate in water and a $\mathrm{pH}$-dependent solubility as well. Glimepiride is classified under class II according to biopharmaceutical classification system (Frick et al., 1998). This may lead to irreproducible clinical response or therapeutic failure in some cases due to subtherapeutic plasma drug levels (Reven et al., 2010). Until now, the published results on glimepiride solubility improvement have involved microencapsulation of glimepiride by spray congealing technology using hydrophilic meltable carriers (Ilić et al., 2009) and nanocrystal to reduce particle size and stability (Sajeev et al., 2013).

The objective of present study is to prepare inclusion complex of glimepiride with cyclodextrins in different molar ratios by freeze drying method. The inclusion complex was further formulated into tablets by direct compression technique using superdisintegrants primogel and crospovidone in order to increase the solubility of glimepiride for improvement of dissolution rate of the drug in the prepared tablet formulations.

\section{MATERIAL AND METHODS}

Glimepiride was obtained from Cross Chem International Company Switzerland, $\beta$ cyclodextrin from Signa Husada Ltd. Company Indonesia., crospovidone from Dexa Medika Ltd. Company Indonesia and all other exipients such as primogel, aerosil, avicel PH-102, and magnesium stearate were given from Pharmaceutical Technology Laboratory Universitas Islam Indonesia. All materials used are of pharmacopeial grade.

\section{Preparation of $\beta$ - cyclodextrin inclusion complexes}

The preparation of inclusion complex was employed by freeze drying method using freeze dryer Alpha 1-2 LD plus models. Glimepiride with $\beta$ - cyclodextrin in different molar ratios (i.e. 1:1M. 1:2M) were dispersed in ethanol using a laboratory stirrer for $48 \mathrm{~h}$ at room temperature $\left(25^{\circ} \mathrm{C}\right)$ to allow for complex formation and prevent loss of volatiles to the atmosphere. The solution was frozen at $-20^{\circ} \mathrm{C}$ and lyophilized at $-50^{\circ} \mathrm{C}$. The lyophilized samples were stored in sealed containers inside a desiccators (Santos et al., 2015).

\section{FTIR spectroscopy}

FTIR spectroscopy (Nicolet Avatar 360) was used to study the molecular structures of the samples in the wave number range of 400$4000 \mathrm{~cm}^{-1}$. The glimepiride, $\beta$-cyclodextrin and inclusion complexes glimepiride- $\beta$-cyclodextrin were diluted with $\mathrm{KBr}$ mixing powder at $1 \%$ and pressed into transparent slices to be analyzed.

\section{Scanning Electron Microscopy}

SEM (Jeol JSTM T300 models) was employed to analyze the particle shape of raw glimepiride, raw $\beta$-cyclodextrin and inclusion complex of glimepiride- $\beta$-cyclodextrin. Each dry sample was mounted on aluminum stubs using double sided carbon tape and sputtercoated with gold under an argon atmosphere. Then the particle shape and size of each sample was observed and analyzed.

\section{Preparation of tablets}

The complex of glimepiride- $\beta$ cyclodextrin was prepared into tablet by direct compression method containing $2 \mathrm{mg}$ of glimepiride. The complex and all ingredients were properly mixed together. The mixed blend of drug and excipients was then compressed in to tablet by using single punch tablet compression machine (Korsh EK 0). The composition of different tablet formulations are shown in table I. 
Table I. Formulae for preparation of glimepiride $-\beta$-cyclodextrin $(1: 1 \mathrm{M})$ inclusion complex tablets with primogel and crospovidone as disintegrant (quantity for 1 tablet).

\begin{tabular}{|c|c|c|c|c|c|c|c|c|c|c|}
\hline Ingredients (code for complex) & F1 & F2 & F3 & F4 & F5 & F6 & F7 & F8 & F9 & F10 \\
\hline $\begin{array}{l}\text { Glimepiride- } \beta \text {-cyclodextrin inclusion } \\
\text { complexes }(\mathrm{mg})\end{array}$ & 14.7 & 14.7 & 14.7 & 14.7 & 14.7 & 14.7 & 14.7 & 14.7 & 14.7 & 14.7 \\
\hline Primojel (mg) & 2 & 3.5 & 5 & 6.5 & 8 & - & - & - & - & - \\
\hline Crospovidone (mg) & - & - & - & - & - & 2 & 2.75 & 3.5 & 4.25 & 5 \\
\hline Avicel pH 102 (mg) & 81.3 & 79.8 & 78.3 & 76.8 & 75.3 & 81.3 & 80.5 & 79.5 & 79.1 & 78.3 \\
\hline Magnesium stearate & 1 & 1 & 1 & 1 & 1 & 1 & 1 & 1 & 1 & 1 \\
\hline Aerosil (mg) & 1 & 1 & 1 & 1 & 1 & 1 & 1 & 1 & 1 & 1 \\
\hline Total quantity (mg) & 100 & 100 & 100 & 100 & 100 & 100 & 100 & 100 & 100 & 100 \\
\hline
\end{tabular}

\section{Evaluation of tablet}

The prepared tablets were evaluated for weight variation, hardness, friability, and disintegration time. The USP weight variation test is done by weighing 20 tablets individually, calculating the average weight and comparing the individual weights to the average. The hardness of 10 tablets was determined using the Erweka hardness tester. Friability was determined by first weighing 10 tablets after dusting and placing them in a friability tester (Erweka TA 200), which was rotated for $4 \mathrm{~min}$ at 25rpm. After dusting, the total remaining mass of tablet was recorded and the percent friability was calculated. Disintegration times of six tablets per formulae were individually determined in a disintegration tester (Erweka ZT 502) containing aquadest at $37 \pm 0.5^{\circ} \mathrm{C}$. The mean disintegration times were calculated.

\section{In vitro dissolution tablets}

In vitro dissolution of tablet was studied in USP XXIV dissolution apparatus (Erweka 708) employing a paddle stirrer in $900 \mathrm{~L}$ of phosphate buffer of $\mathrm{pH} 7.4$ as dissolution medium. The stirrer was adjusted rotate at $75 \mathrm{rpm}$. The temperature of dissolution media was maintained to $37 \pm 0.5^{\circ} \mathrm{C}$. After that, $5 \mathrm{~mL}$ of sample of dissolution medium were withdrawn by means of syringe fitted with prefilter at known intervals of time and analyzed for drug release by measuring the absorbance at $227 \mathrm{~nm}$. The volume withdrawn at each time interval was replaced with fresh quantity of dissolution medium. Percentage amount of glimepiride released was calculated and plotted against time.

\section{RESULTS AND DISCUSSION FTIR spectroscopy}

FTIR spectroscopy is a useful technique to confirm the formation of solid state inclusion complexes because the corresponding peak intensities of the included part of the guest molecules generally get shifted, reduced or sometimes they disappeared. FTIR Spectra of pure drug, $\beta$-cyclodextrin and inclusion complexes of glimepiride with $\beta$-cyclodextrin 1:1 and 1:2 results shown in figure 1.

FTIR spectra inclusion complexes 1:1 and 1:2 $\mathrm{M}$ showed that reduced absorption band $\mathrm{O}-\mathrm{H} \beta$-siklodekstrin from $3385.46 \mathrm{~cm}^{-1}$ to 3371.27 and $3371.49 \mathrm{~cm}^{-1}$. This can be not only due to the vibration frequency of the $\mathrm{O}-\mathrm{H}$ bond of $\beta$-cyclodextrin, but also due to the influence of hydrogen bonding with the group $\mathrm{C}=\mathrm{O}$ on glimepiride. This is the reason for the decline in vibration frequency indicated by the peak of $\mathrm{C}=\mathrm{O}$ and $\mathrm{O}-\mathrm{H}$ are declining at an inclusion complex of 1:1 and 1:2 M. Inclusion cemplexes 1:1 and 1:2 $\mathrm{M}$ also reduced absorption band $\mathrm{C}=\mathrm{O}$ of glimepiride from $1674.0 \mathrm{~cm}^{-1}$ to $1669.56 \mathrm{~cm}^{-1}$ dan $1669.47 \mathrm{~cm}^{-1}$. Molecular interactions between the glimepiride$\beta$-cyclodextrin can occur through hydrogen bonding and Van der Waals bonding. Hydrogen bonding will occur between polar compounds with $\beta$-cyclodextrin glimepiride. Van der Waals bonding will occur between non-polar compounds with glimepiride- $\beta$ cyclodextrin.

The above data proved that there has been the formation of complexes between glimepiride- $\beta$-cyclodextrin with a weak bond. 


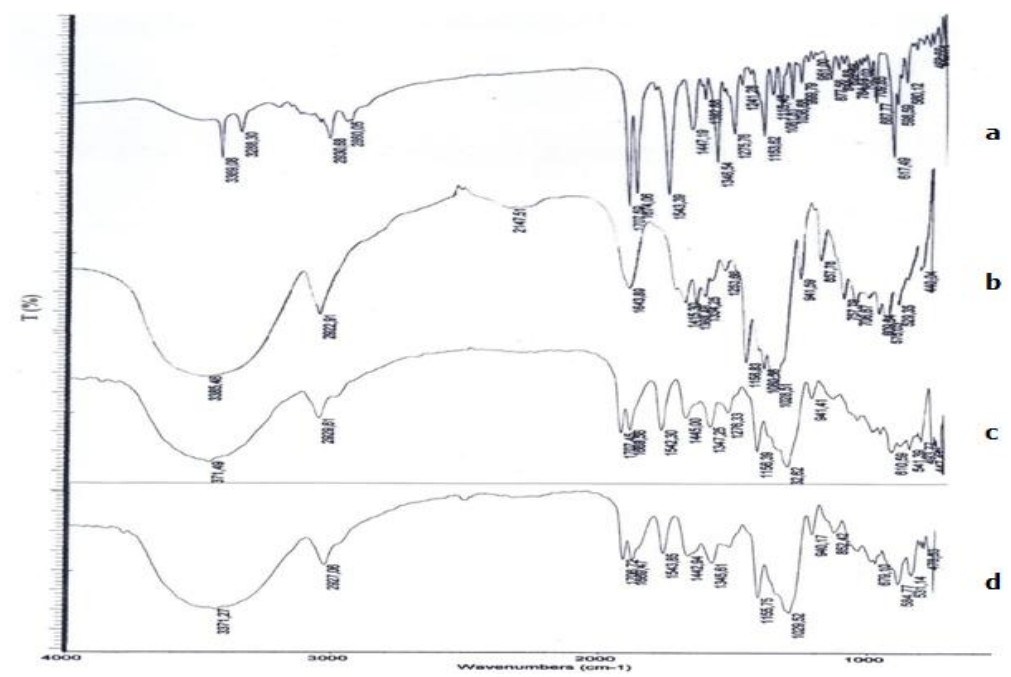

Figure 1. FTIR spectra of each sample, (a) glimepiride; (b) $\beta$-cyclodextrin; (c) complexes of glimepiride with $\beta$-cyclodextrin 1:1 and (d) complexes of glimepiride with $\beta$-cyclodextrin 1:2


Figure 2. SEM images of (a) glimepiride, (b) $\beta$-cyclodextrin, (c) inclusion complex glimepiride- $\beta$ cyclodextrin 1:1 M, and (d) inclusion complex glimepiride- $\beta$-cyclodextrin 1:2 M.

The interaction occured was only physical contact between glimepiride and $\beta$-cyclodextrin molecules, therefore chemical structure of glimepiride unchanged. Recrystallization glimepiride and $\beta$-cyclodextrin simultaneously occured in the process of freeze drying causes glimepiride will be entered into $\beta$-cyclodextrin cavities to formed inclusion complexes.

\section{Scanning Electron Microscopy.}

Figure 2 showed that, glimepiride has been covered by $\beta$-cyclodextrin after mixing process using freeze drying method. Glimepiride was originally flake-shaped surface. The shape changed after a complex process using $\beta$-cyclodextrin inclusion into an amorphous. The shape of the slab has become 
Yandi Syukri

Table II. Evaluation of tablets containing glimepiride- $\beta$-cyclodextrin inclusion complex $1: 1 \mathrm{M}$.

\begin{tabular}{ccccc}
\hline $\begin{array}{c}\text { Formulation } \\
\text { Code }\end{array}$ & $\begin{array}{c}\text { Weighted } \\
\text { average }(\mathbf{m g})\end{array}$ & Hardness (kg) & $\begin{array}{c}\text { Friability } \\
\mathbf{( \% )}\end{array}$ & $\begin{array}{c}\text { Disintegration } \\
\text { time (sec) }\end{array}$ \\
\hline F1 & $102.05 \pm 1.19$ & $4.91 \pm 0.35$ & $0.06 \pm 0.03$ & $37.33 \pm 2.31$ \\
F2 & $101.45 \pm 0.89$ & $5.28 \pm 0.26$ & $0.03 \pm 0.03$ & $30.00 \pm 1.00$ \\
F3 & $99.10 \pm 1.07$ & $4.34 \pm 0.14$ & $0.05 \pm 0.00$ & $27.33 \pm 2.31$ \\
F4 & $98.15 \pm 0.93$ & $5.51 \pm 0.18$ & $0.05 \pm 0.00$ & $26.67 \pm 1.16$ \\
F5 & $100.80 \pm 1.54$ & $5.41 \pm 0.29$ & $0.07 \pm 0.03$ & $24.33 \pm 0.58$ \\
F6 & $102.35 \pm 2.75$ & $5.32 \pm 0.36$ & $0.01 \pm 0.00$ & $72.33 \pm 2.08$ \\
F7 & $101.20 \pm 2.58$ & $5.27 \pm 0.35$ & $0.01 \pm 0.00$ & $28.00 \pm 0.82$ \\
F8 & $102.60 \pm 1.63$ & $4.72 \pm 0.29$ & $0.01 \pm 0.00$ & $27.67 \pm 0.94$ \\
F9 & $103.35 \pm 1.42$ & $5.18 \pm 0.35$ & $0.01 \pm 0.00$ & $24.67 \pm 1.25$ \\
F10 & $103.90 \pm 1.17$ & $4.97 \pm 0.45$ & $0.01 \pm 0.00$ & $23.33 \pm 1.89$ \\
\hline
\end{tabular}

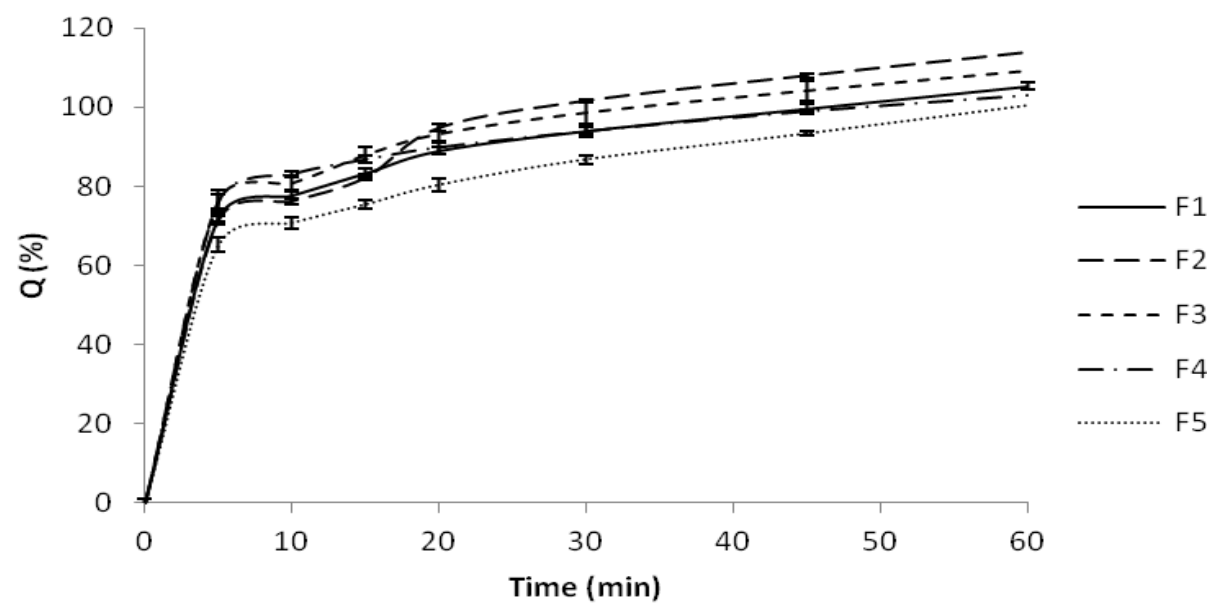

Figure 3. Dissolution profile of inclusion complex tablets with primogel as disintegrant

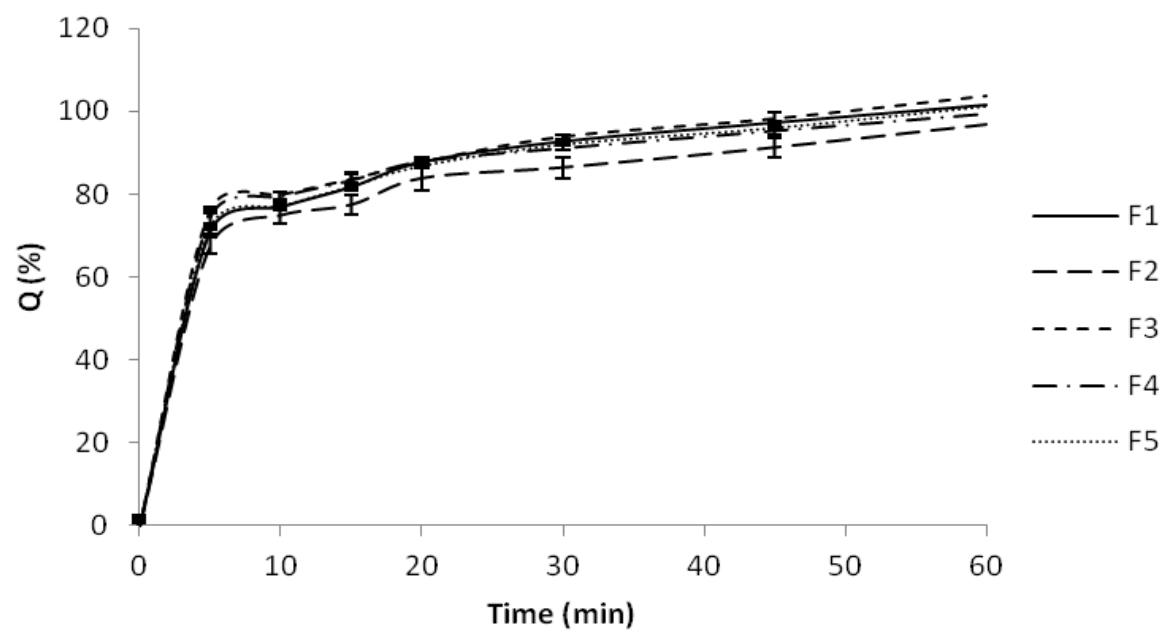

Figure 4. Dissolution profile of inclusion complex tablets with crospovidone as disintegrant 
increasingly apparent in the inclusion complex of $1: 2 \mathrm{M}$. This can be due to the inclusion complex of 1:2M contains concentrations of $\beta$ cyclodextrin are more than the inclusion complex of $1: 1 \mathrm{M}$. The above figure proved that the inclusion complexes formed during recrystallization of glimepiride and $\beta$ cyclodextrin causing glimepiride entering into hydrophobic cavity of $\beta$-cyclodextrin.

\section{Evaluation of tablet}

Table II showed that a good degree of uniformity of weight for all formulations prepared. It is also clear from the tables that all the tablets exhibited good mechanical properties with regard to both hardness and friability. Disintegration time showed that, the increased of primogel and crospovidone concentration will increased time for disintegration of the tablets. This finding can be explained by the fact that primogel have rapid water absorption followed by the ability of a high swell when exposed to water so that the particles making up the tablet broke and can accelerate the disintegration time of tablets. The more concentration primogel used the faster tablets disintegrate. Crospovidone having a porous particle morphology to facilitate water enters the capillary action (wicking) and its rapid return to the initial structure after expands create increased hydrostatic pressure so as to accelerate the process of disintegration. The above data also shows that the ability of primogel and crospovidone have relatively equal good disintegrant, although each has a different mechanism.

\section{In vitro dissolution studies}

As shown in figure 3 and 4, the primogel and crospovidone as disintegrant in tablet formulation had similarity effects on dissolution profile. The inclusion complexes tablet showed that the glimepiride immediately released with high dissolution rate. United State Pharmacopeia (USP) 32 presupposed that glimepiride tablets must be dissolved not less than $80 \%$ within $45 \mathrm{~min}$ of the amount stated on the label. The dissolution results showed that all formulas fulfil Pharmacopeia requirement.

Dissolution test data indicated that primogel and crospovidone can be used as disintegrant in tablet formulations containing poorly soluble glimepiride with $\beta$-cyclodextrin inclusion complexes. In addition to meet the requirements of pharmacopeia, inclusion complexes tablet glimepiride- $\beta$-cyclodextrin also showed immediately drug released because $80 \%$ of drug has been released before $10 \mathrm{~min}$.

\section{CONCLUSIONS}

The $\beta$-cyclodextrins can be used to prepare inclusion complex of glimepride with improved solubility of the drug by freeze drying method. All inclusion complexes tablet produced good quality and meet the requirement of pharmacopeia. The inclusion complexes tablets also showed high drug release indicated by dissolution profile.

\section{ACKNOWLEDGEMENTS}

The authors are thankful to Pharmaceutical Laboratory, Department of Pharmacy Universitas Islam Indonesia for providing the facilities to carry out the work.

\section{REFFERENCES}

Ammar HO., Salama HA., Ghorab M., Mahmoud AA., 2006. Implication of inclusion complexation of glimepiride in cyclodextrin-polymer systems on its dissolution, stability and therapeutic efficacy. Int. J. Pharm. 320 : 53-57.

Challa R., Ahuja A., Ali J., Khar RK., 2005. Cyclodextrins in drug delivery: An updated review. AAPS PharmSciTech 6 : E329-E357.

Figueiras A., Carvalho RA., Ribeiro L., TorresLabandeira JJ., Veiga FJB., 2007. Solidstate characterization and dissolution profiles of the inclusion complexes of omeprazole with native and chemically modified $\beta$-cyclodextrin. Eur. J. Pharm. Biopharm. 67 : 531-539.

Frick A., Möller H., Wirbitzki E., 1998. Biopharmaceutical characterization of oral immediate release drug products. In vitro/in vivo comparison of phenoxymethylpenicillin potassium, glimepiride and levofloxacin. Eur. J. Pharm. Biopharm. 46 : 305-311.

Ilić I., Dreu R., Burjak M., Homar M., Kerč J., Srčič S., 2009. Microparticle size control and glimepiride microencapsulation 
using spray congealing technology. Int. J. Pharm., Challenges in Nano- Micro- and Macro-Systems 381 : 176-183.

Kawabata Y., Wada K., Nakatani M., Yamada S., Onoue S., 2011. Formulation design for poorly water-soluble drugs based on biopharmaceutics classification system: Basic approaches and practical applications. Int. J. Pharm. 420 : 1-10.

Krishnaiah SRY., 2010. Pharmaceutical Technologies for Enhancing Oral Bioavailability of Poorly Soluble Drugs. J. Bioequivalence Bioavailab. 02 : 28-36.

Lee CW., Kim SJ., Youn YS., Widjojokusumo E., Lee YH., Kim J., Lee YW., Tjandrawinata RR., 2010. Preparation of bitter taste masked cetirizine dihydrochloride/ $\beta$-cyclodextrin inclusion complex by supercritical antisolvent (SAS) process. J. Supercrit. Fluids 55 348357.

Liu M., Cao W., Sun Y., He Z., 2014. Preparation, characterization and in vivo evaluation of formulation of repaglinide with hydroxypropyl- $\beta$-cyclodextrin. Int. J. Pharm. 477 : 159-166.

Michel D., Chitanda JM., Balogh R., Yang P., Singh J., Das U., El-Aneed A., Dimmock J., Verrall R., Badea I., 2012. Design and evaluation of cyclodextrin-based delivery systems to incorporate poorly soluble curcumin analogs for the treatment of melanoma. Eur. J. Pharm. Biopharm. 81 : 548-556.

Ramadhani N., Shabir M., McConville C., 2014. Preparation and characterisation of Kolliphor® P 188 and P 237 solid dispersion oral tablets containing the poorly water soluble drug disulfiram. Int. J. Pharm. 475 : 514-522.

Reven S., Grdadolnik J., Kristl J., Žagar E., 2010. Hyperbranched poly(esteramides) as solubility enhancers for poorly watersoluble drug glimepiride. Int. J. Pharm. 396 : 119-126.
Sajeev KB., Saraswathi R., Dhanaraj SA., 2013. Solid-state characterization studies and effect of PEG 20000 and P90G on particle size reduction and stability of complexed glimepiride nanocrystals. J. Young Pharm. 5 : 83-89.

Santos EH., Kamimura JA., Hill LE., Gomes CL., 2015. Characterization of carvacrol beta-cyclodextrin inclusion complexes as delivery systems for antibacterial and antioxidant applications. LW'T - Food Sci. Technol. 60 : 583-592.

Saravana KK., Sushma M., Prasanna RY., 2013. Dissolution Enhancement of Poorly Soluble Drugs by Using Complexation Technique-A Review. J. Pharm. Sci. Res. 5.

Savjani KT., Gajjar AK., Savjani JK., 2012. Drug Solubility: Importance and Enhancement Techniques. Int. Sch. Res. Not. 2012 : e195727.

Shanmuga PA., Sivakamavalli J., Vaseeharan, B., Stalin T., 2013. Improvement on dissolution rate of inclusion complex of Rifabutin drug with $\beta$-cyclodextrin. Int. J. Biol. Macromol. 62 : 472-480.

Sunil SA., Srikanth MV., Rao NS., Raju V., Murthy KVR., 2012. Investigation on in vitro dissolution rate enhancement of indomethacin by using a novel carrier sucrose fatty acid ester. $D A R U J$. Pharm. Sci. $20: 4$.

Taupitz T., Dressman JB., Buchanan CM., Klein S., 2013. Cyclodextrin-water soluble polymer ternary complexes enhance the solubility and dissolution behaviour of poorly soluble drugs. Case example: Itraconazole. Eur. J. Pharm. Biopharm. 83 : 378-387.

Yao Y., Xie Y., Hong C., Li G., Shen H., Ji G., 2014. Development of a myricetin/hydroxypropyl- $\beta$-cyclodextrin inclusion complex: Preparation, characterization, and evaluation. Carbobydr. Polym. 110 : 329-337. 